Original Research Paper

\title{
Optimization of Reinforced Concrete Beams and Steel Beams: A Comparative Study
}

\author{
Joel M. Ozimboski, Zacarias M.C. Pravia and Moacir Kripka* \\ Department of Civil Engineering, University of Passo Fundo, Passo Fundo, Brazil
}

\author{
Article history \\ Received: 16-04-2020 \\ Revised: $18-05-2020$ \\ Accepted: 15-06-2020 \\ Corresponding Author: \\ Moacir Kripka \\ Department of Civil \\ Engineering, University of \\ Passo Fundo, Passo Fundo, \\ Brazil \\ Email: mkripka@upf.br
}

\begin{abstract}
In order to support the structural designer with regard to the selection of structural materials, this work presents results obtained from the optimization of reinforced concrete beams and welded "I" steel beams. To achieve this objective, both problems were formulated according to Brazilian standards, considering the cost as objective function and section dimensions as design variables. For the optimization of the proposed problems, Simulated Annealing optimization algorithm was adopted. Beams were optimized considering spans from 1 up to $25 \mathrm{~m}$ and two different loads. To the structures analyzed, the final costs for steel beams have always been higher than reinforced concrete, but concrete beams are significantly heavier than steel beams.
\end{abstract}

Keywords: Optimization, Steel, Reinforced Concrete, Beams, Structures, Simulated Annealing

\section{Introduction}

With the constant technological evolution and the growing competitiveness of the market, the search for projects that meet the needs of use, comfort and safety of a structure, with the minimum financial resources and environmental impact, becomes part of the engineer's daily life. In this sense, the choice of structural materials should be made based on clear criteria, considering factors such as type of work, availability of materials in the region, skilled labor and available equipment, economic costs, among others. In general, for single-family and multi-story residential buildings, the reinforced concrete structural system is prevalent. In contrast, for structures such as shopping malls, industrial pavilions or warehouses, steel structures have been widely used.

In a structural design, the designer seeks a sizing solution that meets the design's usability, comfort and safety needs while meeting the minimum requirements of technical standards. Within the wide range of possible solutions, obtaining the best-performing trial and error method based on the designer's intuition and experience becomes impractical. In this context, optimization techniques are a valuable support tool for the designer (Dede et al., 2019).

According to (Rahmanian et al., 2014), the optimization of structural design has been greatly driven by economic implications and the greater demand of construction to design satisfactory performance structures with reduced costs. From the point of view of (Sarma and Adeli, 2002), the ideal goal for cost optimization should also take into account the life cycle cost of the structure, considering design, construction, operation and maintenance costs over its useful life. Additionally, in addition to the search for the global optimum, optimization can also be used to obtain alternative solutions that have not yet been imagined or tested, in order to improve the performance of the already known or previously proposed.

In order to support the structural designer with regard to the selection of structural materials, this work presents results obtained from the optimization of reinforced concrete beams and welded "I" steel beams. For increasing spans beams are compared in terms of cost, height and selfweight, using computational tools developed by the authors.

The current technical literature is rich in studies and research regarding the optimization of reinforced concrete beams (Garcia-Segura et al., 2014; Rahmanian et al., 2014; Kripka et al., 2014; Santoro and Kripka, 2020) and steel beams (Drehmer et al., 2008). However, besides the work of (Merta et al., 2008), the authors do not know any study that compares elements dimensioned and optimized with these two materials.

The remainder of this paper is organized as follows. Next chapter presents the formulations to the optimization of steel beams and reinforced concrete beams. After this, some numerical simulations are presented in order to identify the main differences in relation to costs, heights and self-weight between optimized beams. Finally, some important conclusions are pointed. Among them, it was observed that, although heavier that steel beams, reinforced concrete beams led to cheaper elements to all performed simulations. 


\section{Formulations of Optimization Problems}

The formulation adopted to the optimization of reinforced concrete beams was developed according to Brazilian Standard (ABNT, NBR 6118, 2014) by the third author of the present study (Medeiros and Kripka, 2013). The objective function is composed by the total cost of the beam, considering the cost of concrete $\left(C_{c}\right)$, $500 \mathrm{MPa}$ steel $\left(C_{s 50}\right)$ to longitudinal reinforcement, 600 MPa steel $\left(C_{s 60}\right)$ to shear reinforcement and the cost of formworks $\left(C_{f}\right)$. Thus, the objective can be defined as the minimization of the function expressed in Equation (1):

$$
\begin{aligned}
& \text { fobiective }(x)=\left(V_{c} \cdot C_{c}\right)+\left(A_{s 50} \cdot L \cdot \gamma_{s} \cdot C_{s 50}\right)+ \\
& \left(A_{s 60} \cdot L \cdot \gamma_{s} \cdot C_{s 60}\right)+(b+2 h) \cdot L \cdot C_{f}
\end{aligned}
$$

Being:

$L=$ Beam length

$Y_{s}=$ Steel specific weight

$B=$ Beam width

$H=$ Beam height

The constraints of the problem are listed in the sequence, where Equation (2) corresponds to neutral axis limits in relation to effective height of beam to obtain a balanced beam (in which the tension steel reaches yield strain simultaneously as the concrete reaches the failure strain); Equation (3) and (4) correspond to limits of longitudinal and transversal steel areas given by standards. Equation (5) and (6) are related to shear stresses, by comparing the working stresses respectively to compressed struts and to reinforcements in the tensioned struts. Equation (7) corresponds to bending moments. Finally, Equation (8) corresponds to the limitation to maximum displacement. Although elastic linear analysis was considered to stresses, the deformations are calculated considering cracking of concrete, in addition to long term effects:

$$
\begin{aligned}
& 0.259<\frac{x}{d} \leq 0.628 \\
& A_{s, \text { min }} \leq A_{s T} \leq A_{s, \text { max }} \\
& A_{s w, \text { min }} \leq A_{s w} \leq A_{s w, \text { max }} \\
& M_{d} \leq M_{r d} \\
& V_{s d} \leq V_{c} \\
& V_{s d} \leq V_{r d 2} \\
& \delta_{t} \leq \delta_{\text {lim }}
\end{aligned}
$$

$$
\begin{array}{ll}
\text { Being: } & \\
\begin{array}{ll}
x & =
\end{array} \text { Neutral axis } \\
d & =\text { Height of beam }
\end{array}
$$

$$
\begin{array}{ll}
A_{s, \min } & =\text { Minimum steel area } \\
A_{s, \max } & =\text { Maximum steel area } \\
A_{s w, \min } & =\text { Minimum transversal steel area } \\
A_{s w, \max } & =\text { Maximum transversal steel area } \\
M_{d} & =\text { Acting bending moment } \\
M_{r d} & =\text { Resistant bending moment } \\
V_{s d} & =\text { Acting shear stress } \\
V_{c} & =\text { Compressed struts } \\
V_{r d 2} & =\text { Reinforcement in tensioned struts } \\
\delta_{t} & =\text { Total displacement } \\
\delta_{\mathrm{lim}} & =\text { Limit displacement }
\end{array}
$$

The height of the beam was taken as the design variable, while the width remains fixed. To the optimization of steel beams, a formulation was developed and implemented by the second author, according to Brazilian code (ABNT, NBR 8800, 2008). The objective function consists in minimizing the total cost of the beam of section $A_{s}$ and length $L$, being $C_{s}$ the steel unit cost:

$$
f_{o b j}(x)=A_{s} \cdot L \cdot C_{s}
$$

Welded I-shaped profiles with double symmetry were considered, being the cross sectional dimensions the design variables, where: $b_{f}=$ flange width, $h=$ web height and $t_{f}$ and $t_{w}$ are the thickness of flange and web, respectively, as illustrated in Fig. 1. The constraints are described by Equations (10) to (17):

$$
\begin{aligned}
& M_{r d} \geq M_{c s d} \\
& V_{r d} \geq V_{c s d} \\
& \delta \leq \delta_{\lim }
\end{aligned}
$$

$150 \mathrm{~mm} \leq d \leq 2.000 \mathrm{~mm}$

$6.35 \mathrm{~mm} \leq t_{f} \leq 50 \mathrm{~mm}$

$4.75 \mathrm{~mm} \leq t_{w} \leq 50 \mathrm{~mm}$

$b_{f} \leq d \leq 4 b_{f}$

$t_{w} \leq t_{f}$

Being:

$M_{r d}=$ Resistant bending moment

$M_{c e d}=$ Acting bending moment

$V_{r d}=$ Resistant shear stress

$V_{c s d}=$ Acting shear stress

$\delta=$ Maximum displacement

$\delta_{\text {lim }}=$ Limit displacement

$d=$ Total height

$t_{f} \quad=$ Flange thickness

$b_{f} \quad=$ Flange width

$t_{w}=$ Web thickness 


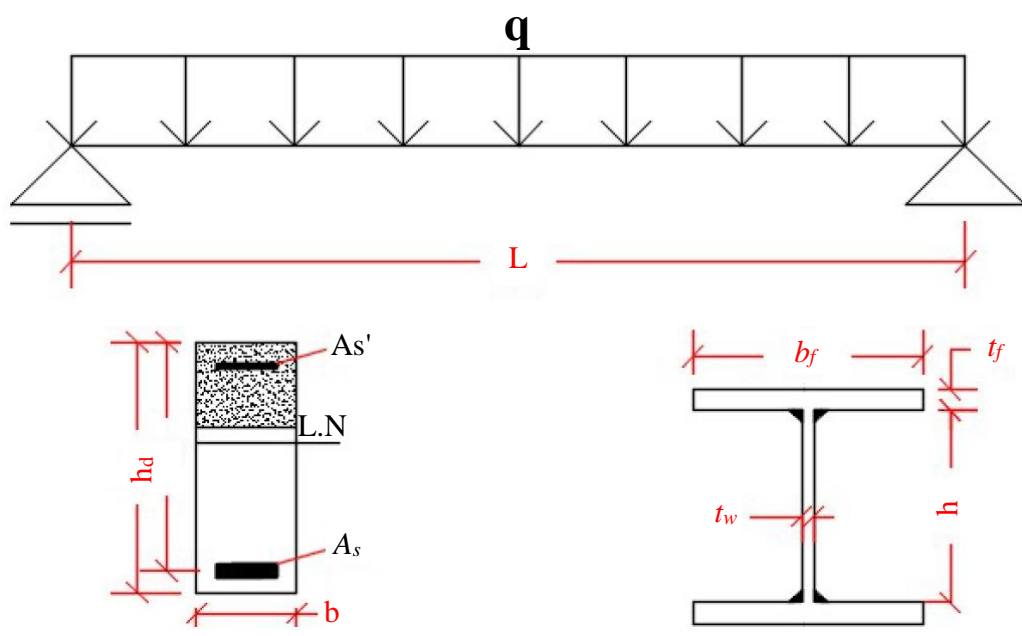

Fig. 1: Problem studied

The constraints described by Equation (9) to (11) correspond to the verification of ultimate limit states, where the strength to bending moment $M_{r d}$ and shear stress $V_{r d}$ must be greater or equal their corresponding acting stresses $M_{c s d}$ and $V_{c s d}$. Equation (12) corresponds to maximum displacement limitation. Equation (13) consists in a manufacturing limitation related to welding process. Equation (14) and (15) fix lower and upper thickness limits to available market values. Finally, Equation (16) and Equation (17) limit the section dimensions according to the standard (ABNT, NBR 5884, 2000).

Both formulations were implemented by the usage of Simulated Annealing optimization algorithm. Simulated Annealing is a heuristic method developed in analogy of the mechanical process of annealing applied to metals. This method, originally proposed by (Kirkpatrick et al., 1983), has as main advantage the reduced number of control parameters regarding other widely used methods such as genetic algorithms, particle swarm and harmony search (Kripka, 2004).

Once only simply supported beams were considered, the stresses and displacements were obtained directly from analytic expressions.

\section{Numerical Simulations}

\section{Problem Studied}

The formulations were applied to the dimensioning of simply supported beams with different spans. It was considered a uniform load over the span length L, composed by dead load of $16 \mathrm{KN} / \mathrm{m}$ and live load of $7 \mathrm{KN} / \mathrm{m}$. Self-weight was automatically computed and added to dead loads.

The costs considered to materials were the following: cost of concrete fck $30 \mathrm{MPa}$ : US\$ $91.21 / \mathrm{m}^{3}$, cost of steel $500 \mathrm{MPa}$ : US\$ $1.47 / \mathrm{Kg}$, cost of steel $600 \mathrm{MPa}$ : US\$ $2.00 / \mathrm{Kg}$ and cost of formworks: US\$ $22.15 / \mathrm{m}^{2}$.
For the cost of concrete, the costs of launching with a pump truck, density and finishing were considered. Likewise, the cost of steel is composed of the value of the material and also the labor and other items necessary for cutting, bending and assembling a structural element. Because this study is working only with the steel area, without considering the diameters to be used, the average market value to steel bars was adopted, for gauges ranging from 6.3 to $20 \mathrm{~mm}$. The cost of the formwork takes into account the value of the material and the labor (sawn wood and metallic support). The reuse of formwork was also considered. For the steel profiles, the unit cost of the finished metallic structure, in "I" profile, was considered. The cost composition takes into account the supply of steel sheets, materials and inputs for the execution of welding and assembly, including labor.

\section{Optimum Cost of Reinforced Concrete Beams}

To the adopted formulations, simply supported beams were analyzed considering minimum and maximum loads and spans ranging from 1 to $25 \mathrm{~m}$. The beam width was fixed as $15 \mathrm{~cm}$.

At first, the design was made limiting the displacements for effects on non-structural elements (L/350), according to NBR 6118: 2017. The optimal cost is illustrated in Fig. 2. It can be observed that the difference in the optimal cost regarding minimum and maximum loads is lower than $15 \%$ and that the optimized dimensioning had the displacements limitation as the active constraint for all spans and loads.

The height that leads to the optimum cost of the beam has the behavior of a polynomial function of degree 2, as shown in Fig. 3. For the minimum load, the average for the height/span ratio was aproximately 11 to spans from 1 to $12 \mathrm{~m}$, while for 13 to $25 \mathrm{~m}$ the average ratio was 15 . At maximum load, the ratio is slightly higher, being 14 for the first interval and 18 for the second. 
In the composition of the total cost, formwork represents the highest percentage in relation to the final cost (about 65\%), followed by concrete and steel, respectively. In an alternative situation, the cost of formwork was considered as US\$15.92, corresponding to 6 reuses instead of 2, as originally adopted. For this consideration, naturally the total cost was slightly lower and consequently the representativeness of the formworks decreased to values below $60 \%$ in relation to the total cost. Nevertheless, this variation didn't generate any change in the optimized dimensions of the beam.

\section{Optimum Cost of Steel Beams}

Similar to reinforced concrete beams, steel beams were optimized for increasing spans from 1 to $25 \mathrm{~m}$. Fig. 4 illustrates the optimized costs corresponding to the loads and spans considered.

Contrary to reinforced concrete beams, the displacements were not the active constraints for the spans considered. The optimal height of the sections varied from between 8 to $4 \%$ of the span, with the lowest ratio for larger spans Fig. 5.

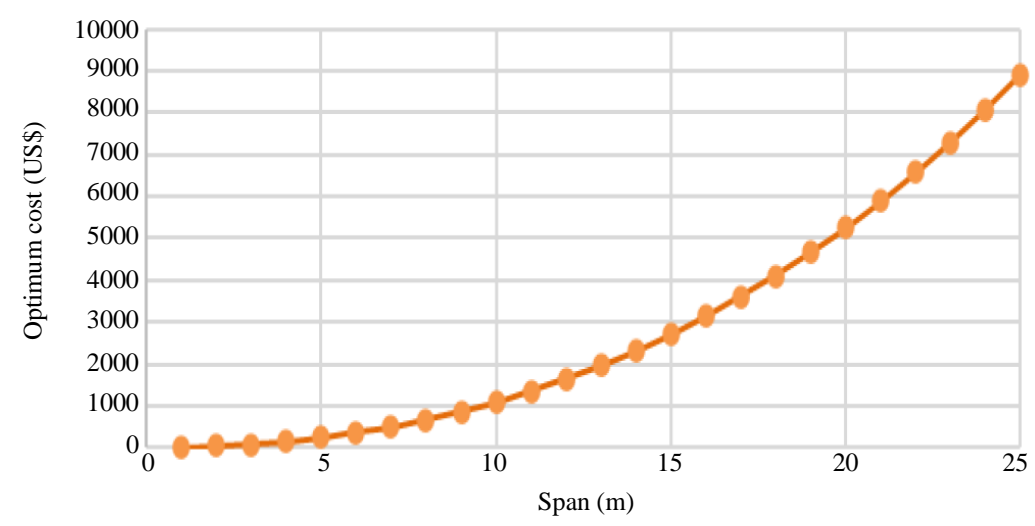

Fig. 2: Optimum cost to RC beams

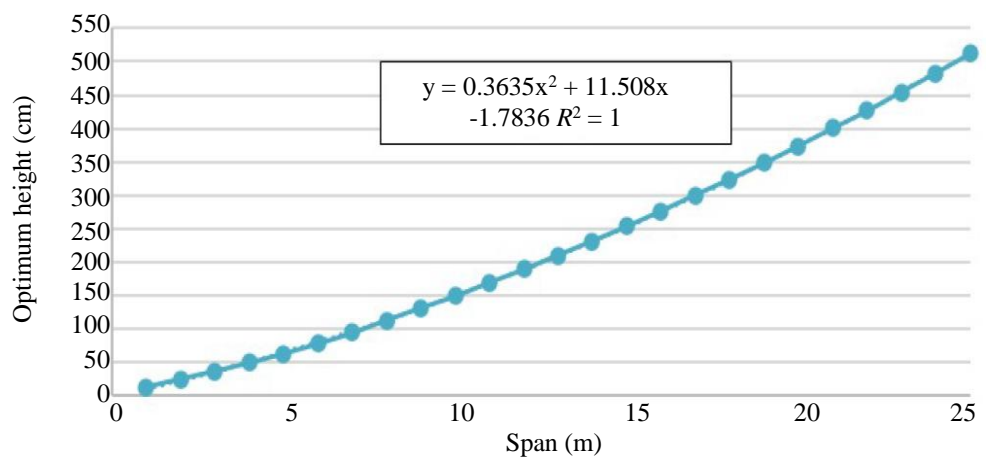

Fig. 3: Optimum section height

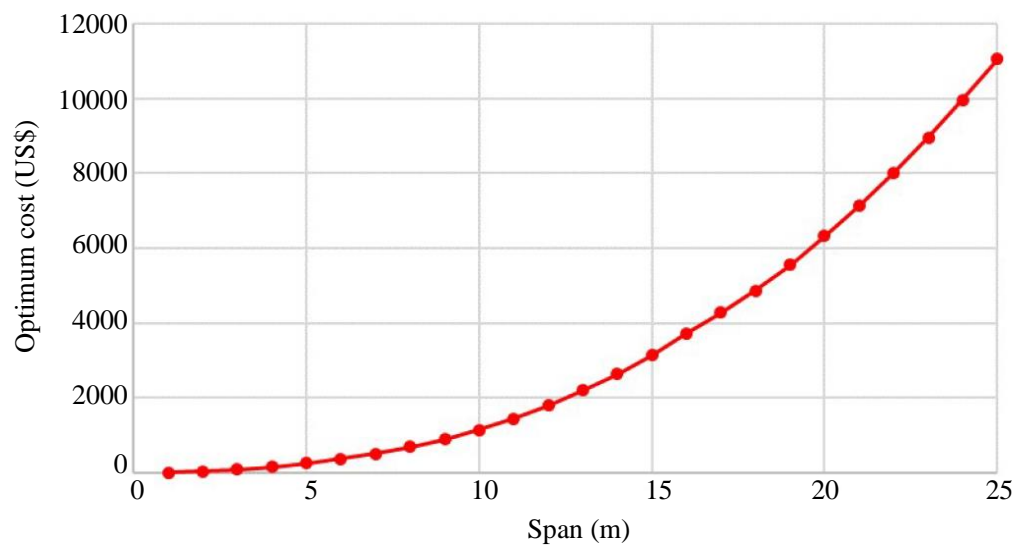

Fig. 4: Optimum cost to steel beams (I profile) 
Comparison of Reinforced Concrete Beams and Steel Beams

The optimal cost obtained through the optimized design for both types of beams generated a very similar behavior, as can be seen in Fig. 6. Figure 7 illustrates the difference between steel cost and reinforced concrete cost. It can be noticed that for small spans the optimized cost doesn't represent significant differences for the different types of beam. On the other hand, for largest span the steel beam is almost $25 \%$ more expensive than the reinforced concrete beam. Regarding the optimized heights Fig. 8, the differences are quite expressive, especially for spans over $10 \mathrm{~m}$.

Figure 9 shows the self-weight of beams, where a huge difference between the self-weight for the different types of beam can be observed. Reinforced concrete beams were much heavier than the steel ones, reaching differences greater than 6 times for the largest spans. For spans of less than $10 \mathrm{~m}$ the self-weight has less expressive differences, but is still quite significant.

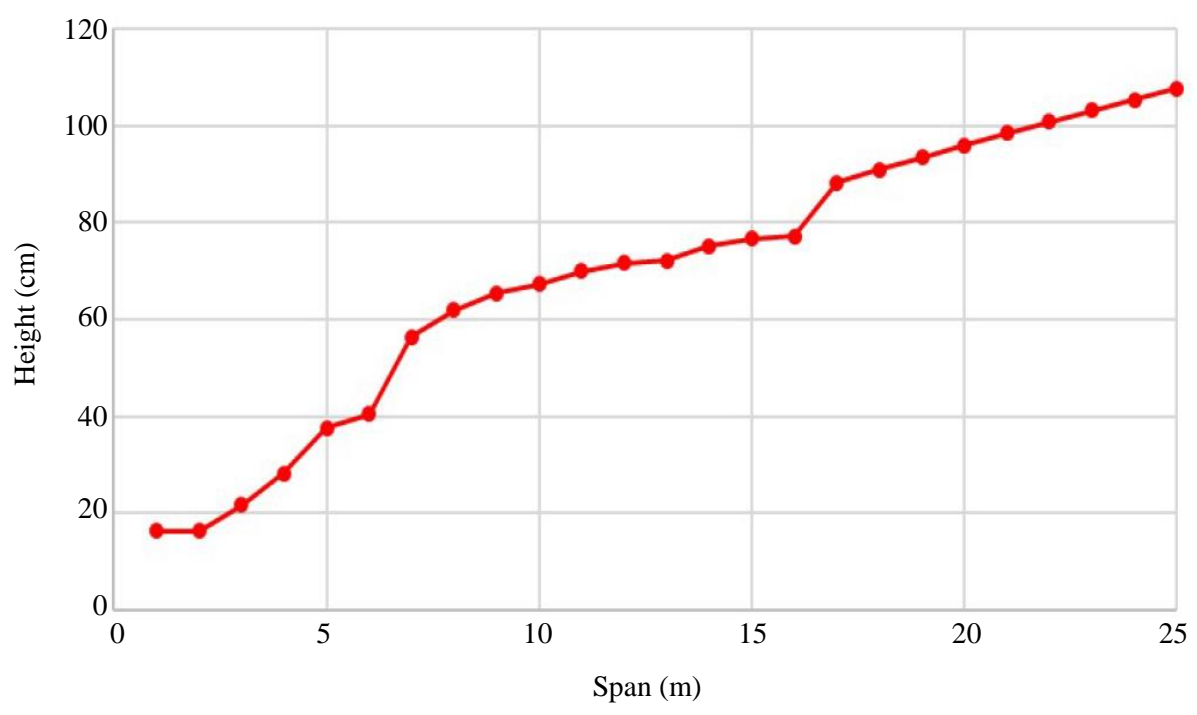

Fig. 5: Optimum height to steel beams

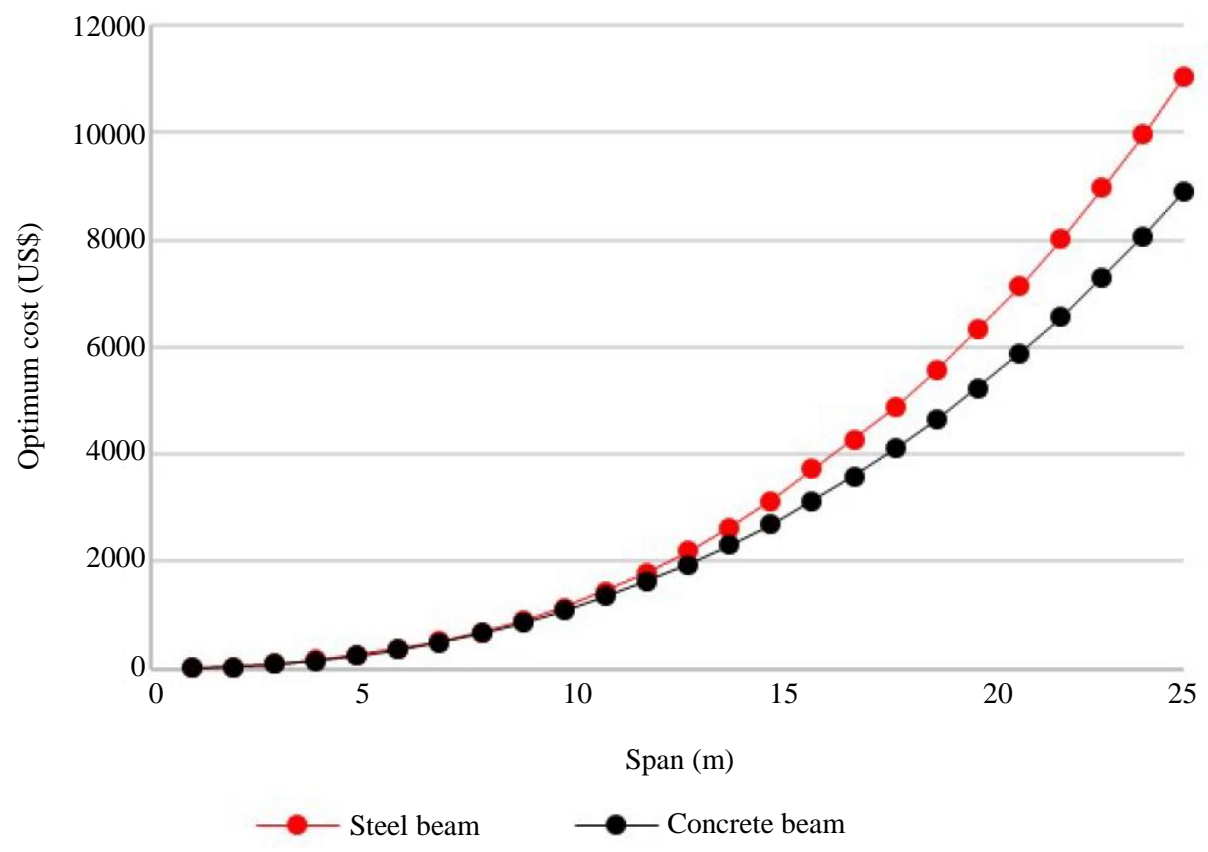

Fig. 6: Optimum cost (steel x concrete) 
1.3

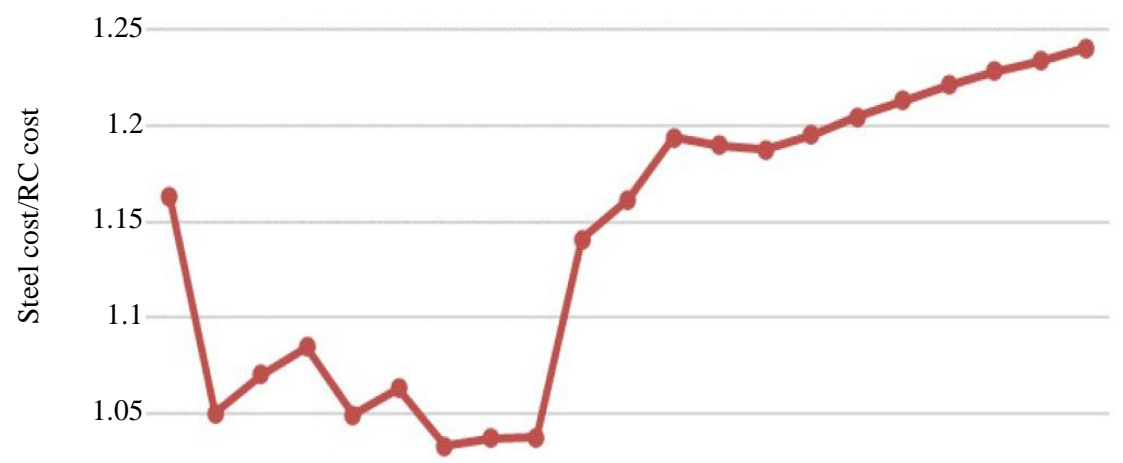

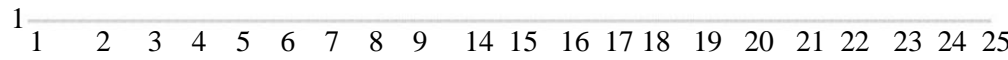

Span $(\mathrm{m})$

Fig. 7: Optimum relative cost (Steel/RC)

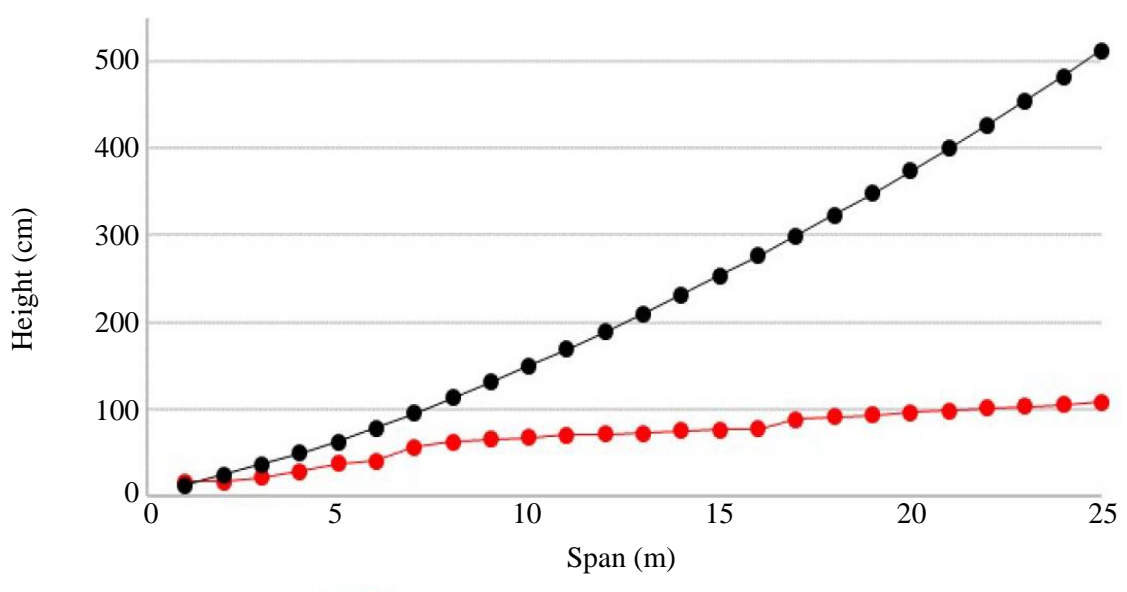

$\longrightarrow$ Steel beam $\rightarrow$ Concrete beam

Fig. 8: Optimum height $($ steel $\times$ concrete $)$

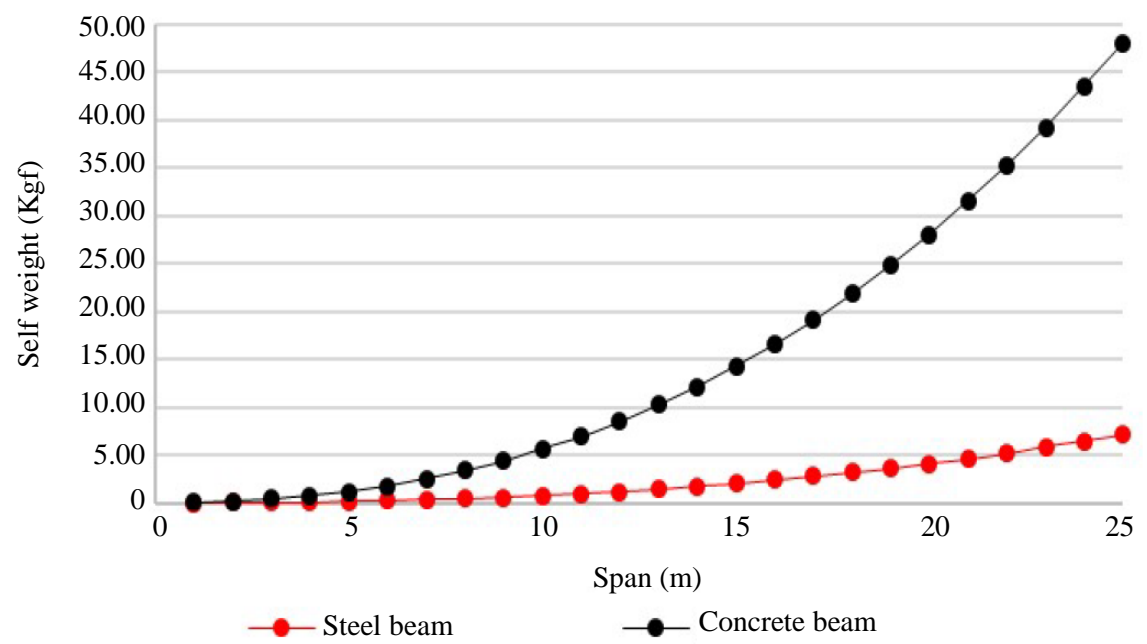

Fig. 9: Self weight $($ steel $\times$ concrete $)$ 


\section{Conclusion}

The present work aimed a comparative study between the optimized design of reinforced concrete and steel beams. To achieve this objective, both problems were formulated according to Brazilian standards, considering the cost as objective function and section dimensions as design variables. For the optimization of the proposed problems, Simulated Annealing optimization algorithm was adopted. Beams were optimized considering spans from 1 up to $25 \mathrm{~m}$ and two different loads. Based on the results, it was observed that the optimal cost behavior for reinforced concrete and steel beams was quite similar for spans up to $25 \mathrm{~m}$. The final costs for steel beams have always been higher than reinforced concrete. In general, for spans of up to $10 \mathrm{~m}$ the difference is not significant, increasing for larger values. For the largest span studied $(25 \mathrm{~m})$ the concrete beam was $19 \%$ cheaper compared to steel. On the other hand, concrete beams are significantly heavier than steel beams, regardless the span considered. In addition, it was observed that, when the height of the beams is an important aspect to be considered, steel beams consists in a good option.

In general, it can be seen that a given material, when compared to others, presents positive and negative characteristics. In this sense, a more comprehensive study considering other aspects by using multi-criteria decision-making methods as in (Kripka et al., 2019), is being performed.

Although the present study considered only simply supported beams, similar methodology can be used to compare other structural materials, configurations and elements. In addition, other aspects such as labor costs can be considered. Despite Brazilian standards were adopted, it can be supposed that the results are valid to other design codes.

\section{Acknowledgement}

The third author acknowledge the financial support of the Brazilian Council for Scientific and Technological Development-CNPq (Grant: 302736/2017-4).

\section{Author's Contributions}

Joel M. Ozimboski: Numerical simulations, manuscript preparation.

Zacarias M.C. Pravia and Moacir Kripka: Computational implementation, manuscript preparation.

\section{Ethics}

This article is original and contains unpublished material. The corresponding author confirms that all of the other authors have read and approved the manuscript and no ethical issues involved.

\section{References}

ABNT, NBR 5884, 2000. Perfil I estrutural de aço soldado por arco elétrico: Especificação. Associação Brasileira de Normas Técnicas. Rio de Janeiro.

ABNT, NBR 6118, 2014. Projeto de estruturas de concreto-Procedimento. Associação Brasileira de Normas Técnicas. Rio de Janeiro.

ABNT, NBR 8800, 2008. Projeto de estruturas de aço e de estruturas mistas de aço e concreto de edifícios. Associação Brasileira de Normas Técnicas. Rio de Janeiro.

Dede, T., M. Kripka, V. Togan and V. Yepes, 2019. Usage of optimization techniques in civil engineering during the last two decades. Curr. Trends Civ. Struct. Eng., 2: 1-17. DOI: 10.33552/CTCSE.2019.02.000529

Drehmer, G.A., M. Kripka and Z.M.C. Pravia, 2008. Dimensioning of welded steel profile beams with optimization techniques (in Portuguese). Construção Metálica, 86: 23-26.

Garcia-Segura, T., V. Yepes, J.V. Marti and J. Alcala, 2014. Optimization of concrete I-beams using a new hybrid glowworm swarm algorithm. Lat. Am. J. Solids Struct., 11: 1190-1205.

DOI: $10.1590 /$ S1679-78252014000700007

Kirkpatrick, S., C.D. Gelatt and M.P. Vecchi, 1983. Optimization by simulated annealing. Science, 220: 671-680.

DOI: $10.1126 /$ science.220.4598.671

Kripka, M., 2004. Discrete optimization of trusses by simulated annealing. J. Brazilian Society Mech. Sci. Eng., 26: 01-04.

DOI: $10.1590 / \mathrm{S} 1678-58782004000200008$

Kripka, M., G.F. Medeiros, J.L.T. Fraga and P.R. Marosin, 2014. Minimizing the environmental impact of R-C structural elements. Proceedings of the 4th International Conference on Engineering Optimization, (EOE’ 14), ACM, pp: 727-730. DOI: $10.1201 / \mathrm{b} 17488-129$

Kripka, M., V. Yepes and C.J. Milani, 2019. Selection of sustainable short-span bridge design in Brazil. Sustainability, 11: 01-12. DOI: $10.3390 / \mathrm{su} 11051307$

Medeiros, G.F. and M. Kripka, 2013. Structural optimization and proposition of pre-sizing parameters for beams in reinforced concrete buildings. Comput. Concrete Int. J., 11: 253-270. DOI: 10.12989/cac.2013.11.3.253 
Joel M. Ozimboski et al. / International Journal of Structural Glass and Advanced Materials Research 2020, Volume 4: 160.167 DOI: 10.3844/sgamrsp.2020.160.167

Merta, I., S. Kravanja and U. Klansek, 2008. Optimization based cost comparison between reinforced concrete and steel beams. High Perform. Struct. Mater., 97: 449- 456.

DOI: $10.2495 / \mathrm{HPSM} 080461$

Rahmanian, I., Y. Lucet and S. Tesfamariam, 2014. Optimal design of reinforced concrete beams: A review. Comput. Concrete, 13: 457-485.

DOI: $10.12989 / \mathrm{cac} .2014 .13 .4 .457$
Santoro, J.F. and M. Kripka, 2020. Minimizing environmental impact from optimized sizing of reinforced concrete elements. Comput. Concrete, 25: 111-118.

Sarma, K.C. and H. Adeli, 2002. Life-cycle cost optimization of steel structures. Int. J. Numer. Meth. Eng., 55: 1451-162. DOI: 10.1002/nme.549 